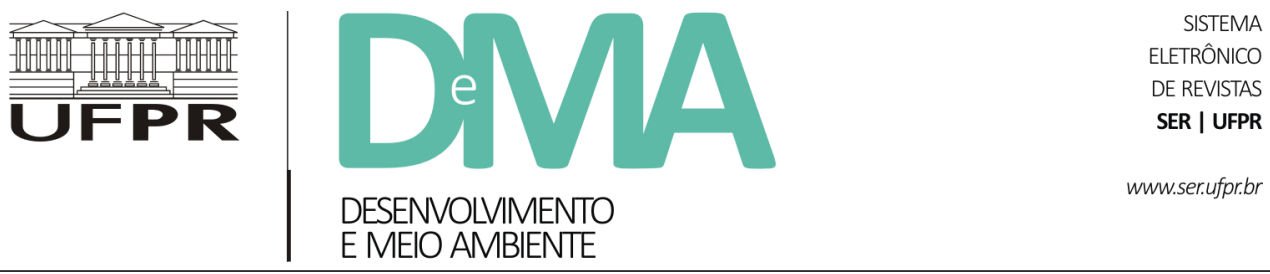

\title{
Mudanças climáticas como um risco construído ou percebido: análise da produção teórica de J. Hannigan e O. Renn no debate da sociologia ambiental ${ }^{1}$
}

\section{Climate Change as a Constructed or Perceived Risk: Analysis of the Theoretical Production by J. Hannigan and O. Renn in an Environmental Sociology Debate}

\author{
Fábio BACCHIEGGA ${ }^{1 *}$ \\ ${ }^{1}$ Instituto de Filosofia e Ciências Humanas (IFCH), Universidade Estadual de Campinas (UNICAMP), Campinas, SP, Brasil. \\ *E-mail de contato: fabiobacc@gmail.com
}

Artigo recebido em 3 de outubro de 2016, versão final aceita em 11 de setembro de 2017.

RESUMO: No mundo contemporâneo, a perspectiva da Sociologia do Risco vem ganhando espaço num ambiente onde compreender o mundo configura-se ter a consciência dos riscos que nos cercam e orientam nossas ações. Este risco trata-se de uma "tendência imanente da globalização", segundo Giddens. A globalização foi um fenômeno capaz de remodelar nossa percepção espaço-tempo, nos "aproximando" de lugares cada vez mais distantes graças as revoluções das tecnologias de informação, serviu também para nos aproximar dos riscos, mundializando-os. Sob essa ótica, nos propomos a tratar de um desses riscos mundializados, especificamente a questão ambiental relacionada com as mudanças climáticas. Este tema, amplamente discutido na arena da ciência e políticas públicas, reorienta práticas e concepções de mundo. Porém, sabemos que a existência do risco das mudanças climáticas passa diretamente pela sua "construção social", como pensa J. Hannigan, ou da sua "percepção", sob a ótica de O. Renn. Neste trabalho, propomos um debate teórico entre os textos de Hannigan e Renn acerca dos riscos presentes no debate ambiental sobre as mudanças climáticas e como estes se apresentam construídos ou percebidos pela sociedade e resultam em efeitos diretos nas ações da população em geral, ou na criação de políticas públicas sobre o tema. Objetivamos assim, ao analisá-los e compará-los, fornecer elementos para enriquecer o debate teórico acerca da Sociologia do Risco associada à emergência do debate socioambiental.

Palavras-chaves: sociologia ambiental; sociologia do risco; mudanças climáticas.

\footnotetext{
${ }^{1}$ Adaptação do artigo apresentado no XVII Congresso da Associação Brasileira de Sociologia, em especial dentro do Grupo de Trabalho (GT) 34: Teoria Sociológica, realizado em Porto Alegre (RS) em 2015.
} 
ABSTRACT: In the contemporary world, the perspective present in the Sociology of Risk has been increasing in an environment where understanding the world sets up to being aware of the risks surrounding us and guide our actions. This risk is an "immanent tendency of globalization," says Giddens. Globalization was a phenomenon able to reshape our space-time perception, "leading us closer" to more distant places through the revolutions of information technology, also serving as a mean to "approach" risks, globalizing them. In this light, we propose to deal with such a globalized risks, specifically climate change related to environmental issues. This issue, widely discussed in the arena of science and public policy, reorient practices and worldviews. However, we know that the existence of the risk of climate change is built upon its "social construction" as believes J. Hannigan, or its "perception" from the prospect of O. Renn. In this paper, we propose a theoretical debate between Hannigan and Renn texts about the risks present in the environmental debate about climate change and how they are built or perceived by society, as well as results in direct effects on the population's actions in general or in creating public policies on the subject. We aim thus to both analyze and compare them, providing elements to enrich the theoretical debate about the Sociologyof Risk, associated with the emergence of the environmental debate.

Keywords: environmental sociology; sociology of risk; climate change.

\section{Introdução}

A discussão ambiental surge nos anos 1960, junto com movimentos de contracultura, das organizações do terceiro setor, da crítica ao modelo de desenvolvimento predatório vigente e ao crescente armamentismo (Ferreira, 2006). Inúmeros estudos, de diferentes áreas, começam a questionar os limites do desenvolvimento e da busca pelo lucro, a crescente degradação dos recursos naturais, a noção questionável de renovabilidade do meio natural e a ação cada vez mais predatória dos Estados na busca do crescimento econômico (Gorz, 1980; Illich, 1976). Nota-se que, nestas discussões e nestes estudos, os impactos ambientais deixam o nível local e se tornam preocupações no nível global.

Assim, a temática ambiental, antes excluída por governos que consideravam sua crítica uma ameaça ao processo de desenvolvimento econômico predatório ou ainda relegada ao segundo plano por inúmeros pesquisadores - mesmo do campo sociológico -, por considerarem este tema de estudo menos importante que tidos como clássicos (luta de classes, por exemplo); acaba ganhando importância e sendo necessário um novo foco sobre o tema, novas reflexões, novos conceitos. Surge, nesse contexto, a chamada Sociologia Ambiental.

Antes um subcampo dos estudos da Sociologia Rural, a Sociologia Ambiental passa a ganhar corpo teórico com a promoção dos debates acerca da dinâmica da interface entre ambiente e sociedade, e estruturar-se como uma área autônoma de estudo. Assim, fortalecendo seus alicerces teóricos e construindo modelos para a percepção da relação entre as sociedades e o ambiente biofísico (Buttel, 1996 apud Ferreira, 2006).

Inúmeras teorias se estabelecem e se estruturam, seja sob um viés mais otimista da dinâmica socioambiental, como a Modernização Ecológica (Mol, 2000; Spaargaren et al., 2000), ou então sob uma percepção mais pessimista, como o Materialismo Marxista (Schnaiberg, 1996). Porém, mantendo uma característica muito presente nos estudos ambientais, que se posicionam com um forte caráter 
universalista desde sua origem e buscam expressar a relação dialética entre as ações humanas sobre o meio biofísico e as reações deste meio natural sobre diferentes atores sociais muitas vezes em escalas globais, fato que vem se amplificando com o advento dos debates sobre Globalização e Risco nas últimas décadas.

Uma dessas correntes teóricas importantes trata da perspectiva da Sociologia do Risco, e vem ganhando destaque em um ambiente contemporâneo onde compreender o mundo configura-se ter a consciência dos riscos que nos cercam e orientam nossas ações. Riscos aqui compreendidos sob seu aspecto multifacetado e amplo, como ameaças associadas ao terrorismo internacional, à profusão de epidemias ou, como trataremos adiante, às mudanças climáticas.

Já o contexto da globalização, foi um fenômeno capaz de remodelar nossa percepção espaço-tempo, nos aproximando de lugares cada vez mais distantes graças as revoluções das tecnologias de transporte e informação (Ianni,1995; Ortiz, 2006), mas serviu também para nos aproximar dos riscos, mundializando-os.

Neste artigo, nos propomos a analisar as interfaces da Sociologia do Risco a do debate da Sociologia Ambiental, em especial dos estudos acerca das mudanças climáticas, sob a ótica dos riscos mundializados no trabalho de dois autores contemporâneos, referências neste debate: John Hannigan (principal responsável pela formação da chamada perspectiva construtivista) e Ortwin Renn (autor que trabalha com a concepção realista).

\section{Mundialização do debate acerca das mudanças climáticas}

Inúmeros fenômenos recentes parecem amplificar a discussão sobre as chamadas mudanças climáticas. Por exemplo, em dezembro de 2015, os olhares da mídia se voltaram para cidade de Paris (França), onde realizou-se a Conferência do Clima, reunindo cerca de 50 mil pessoas de 175 países que firmaram um novo acordo climático, um provável substituto do Tratado de Quioto $^{2}$, para propor ações efetivas para a redução dos GEEs - conhecido como Acordo de Paris.

No debate científico, ânimos se acirram a medida em que alguns cientistas, chamados de "negacionistas" argumentam que a influência humana, na promoção das alterações em escala global na dinâmica climática, é mínima ou até mesmo altamente improvável ${ }^{3}$ e outros, mais alinhados com o discurso do IPCC, tratam a ação antrópica, desde a Revolução Industrial, como a principal causa da amplificação do Efeito Estufa impactando decisivamente o clima global. Porém, mesmo entre os cientistas mais próximos do IPCC não existe consenso em muito temas, como a média prevista do aumento da temperatura a curto prazo, ou as melhores estratégias de adaptação e/ou mitigação

\footnotetext{
${ }^{2}$ O Protocolo de Quioto foi um acordo assinado em 1997 durante a COP3 no Japão que, resumidamente, propunha que seus membros se comprometessem com a redução de 5,2\% das suas emissões de GEES, considerando os níveis de 1990, até 2007. Efetivamente entrou em prática no mês de fevereiro de 2005, mas não atingiu seus objetivos efetivos até os dias de hoje, criando a necessidade de um novo acordo climático para reforçar os compromissos de Quioto que aconteceu em Paris em 2015.

${ }^{3}$ Politicamente, no ano de 2017, a comunidade negacionista ganhou mais influência a medida em que o presidente D. Trump, dos Estados Unidos, segundo maior emissor de gases do efeito estufa do planeta, se posicionou contrário ao Acordo de Paris e retirou a participação de seu país no cumprimento das metas estabelecidas em 2015.
} 
desta problemática ambiental.

Historicamente, desde o século XIX a ideia do Efeito Estufa e a existência de determinados gases se acumulando na atmosfera, e assim ampliando a concentração de calor na Terra, eram temas debatidos e conhecidos ${ }^{4}$. Porém, pouco trabalhados e a margem de tantas descobertas num século tão fértil para a ciência. Somente no século XX, em especial na sua segunda metade, que o debate sobre mudança climática ganha força.

De um lado, a questão ambiental passa a ser mais debatida e forma-se como uma rede considerável nas análises sociais, do outro, novos estudos, como os do climatologista Charles David Keeling (1928-2005) serão determinantes, provando o aumento da concentração de GEEs na atmosfera (Keeling, 1960; 1997) através de medições realizadas por três anos (1957, 1958 e 1959), em três lugares diferentes (Little America na Antártida, La Jolla na Califórnia e no Observatório de Mauna Loa no Havaí) e seu impacto na mudança temperatura média destes lugares.

A partir da década de 70, mundializa-se o debate ambiental graças ao fortalecimento de inúmeros grupos do Terceiro Setor e ações de organismos supranacionais, como a realização Conferência das Nações Unidas para o Meio Ambiente Humano em 1972 (Estocolmo, Suécia). Porém, no final da década de 1980, nasce o organismo responsável pela grande dispersão da questão ambiental das mudanças climáticas, conferindo-lhe o status de tema central no debate ambiental e presente nas mais diferentes esferas de discussão, como mídia e políticas públicas, no caso, a criação do Painel Intergovernamental sobre Mudanças Climáticas (IPCC) no ano de 1988.

A resolução 43/53, da Organizações das Nações Unidas (ONU), de 1988, versa - especificamente - sobre a preocupação com as questões das mudanças climáticas ao afirmar que a instituição estaria convencida do impacto negativo de uma mudança no clima no planeta e propõe, sob o controle da Organização Meteorológica Mundial (WMO, em inglês) e do Programa das Nações Unidas para o Meio Ambiente (PNUMA), a criação de um:

Painel Intergovernamental sobre Mudanças Climáticas para iniciar imediatamente uma ação que conduza, o mais rapidamente possível, uma ampla revisão e recomendações sobre:

(a) O 'estado da arte' sobre as ciências do clima e as mudanças climáticas;

(b) Projetos e estudos sobre os impactos econômicos e sociais das mudanças climáticas, incluindo o aquecimento global;

(c) Possíveis alternativas estratégicas para atrasar, limitar ou mitigar os impactos adversos das mudanças climáticas;

(d) Identificação e possíveis fortalecimentos dos instrumentos jurídicos internacionais relevantes que influenciam o clima;

(e) Elementos para inclusão de uma possível futura convenção internacional sobre o clima; (ONU, 1988, tradução nossa)

\footnotetext{
${ }^{4}$ A expressão "Efeito Estufa" é do início do século XIX quando o matemático Jean Baptiste Joseph Fourier (1768-1830) apresentou dados buscando provar a existência de trocas de calor entre corpos e atmosfera, mostrando como gases poderiam influenciar na temperatura interna da Terra. Estes dados foram comprovados empiricamente por John Tyndall (1820-1893) que, em 1859, apresenta um experimento mostrando como diferentes gases, como água, dióxido de carbono e ozônio, presentes na atmosfera, podem reter maior ou menor quantidade de calor. Mas foi o químico sueco Svante Arrhenius (1859-1927), já no final do século XIX que estabelece uma relação direta entre o aumento a concentração de gases, como dióxido de carbono, poderiam efetivamente levar a um aumento da temperatura no planeta.
} 
A partir desta resolução, surge o Painel Intergovernamental sobre Mudanças Climáticas (IPCC, na sigla em inglês), responsável pela elaboração de diversos relatórios. Geralmente, a cada cinco anos, apresentando a produção de conhecimento sobre mudanças climáticas e as formas de adaptação e mitigação deste fenômeno. O objetivo básico do IPCC e suas ações é:

avaliar de forma abrangente, objetiva, aberta e transparente a informação científica, técnica e socioeconômica relevante para a compreensão da base científica do risco de mudanças climáticas induzidas pelo homem, seus potenciais impactos e opções de adaptação e mitigação. Os relatórios do IPCC devem ser neutros em relação à política, embora possam precisar lidar objetivamente com fatores científicos, técnicos e socioeconômicos relevantes para a aplicação de políticas específicas (IPCC, 2013, p. 1, tradução nossa)

A partir deste escopo formador, cabe aos cientistas do Painel apresentarem um Relatório de Avaliação, uma Síntese dos Resultados e um Resumo para Formuladores de Políticas Públicas (policymakers); reunindo os grandes debates e possíveis conclusões sobre o debate das mudanças climáticas. Estes relatórios vêm ganhando espaço na mídia, transformando-se em notícias e reportagens especiais, atingindo o grande público, difundindo as discussões sobre mudanças climáticas para boa parte da população (Andrade \& Almeida Junior, 2011; Bacchiegga, 2017). Também, é utilizado como base de orientação para diretrizes de pesquisas em Universidades e de formulação de políticas públicas pelos diferentes Estados.

Dito de outra forma, acreditamos que a formação do IPCC amplificou os debates sobre mudanças climáticas e apresentou visibilidade às ações que se apresentaram para mitigar ou adaptar situações e áreas de vulnerabilidade sobre este tema. Esta amplificação resultou na mundialização do tema, afinal trata-se de um impacto ambiental com causas e consequências num nível global, e com instituições estabelecidas que constantemente nutrem os debates com novas pesquisas e considerações das mais diversas sobre o assunto. De temática praticamente irrelevante há décadas atrás, citada raramente dentro de poucos laboratórios no planeta, as mudanças climáticas hoje se apresentam como um tema global e de risco mundializado, constantemente debatido nas mais variadas esferas da sociedade.

\section{A Sociologia do risco sob a perspectiva ambiental}

A palavra "risco" é um vocábulo latino, criado por volta do século XVI e associava-se a ideia que os navegadores portugueses e espanhóis da época tinham sobre os perigos de velejar em águas desconhecidas (Giddens, 1999). Dito de outra forma, o risco em sua gênese associava-se a probabilidade do que se encontraria a frente onde, no caso dos navegadores, referia-se aos aparentes perigos das águas "d'além mar".

Portanto, a noção de risco nos traz - necessariamente - a ideia de incerteza, da noção da inexistência de dados concretos no futuro, porém calculáveis (Giddens, 1991; 2010). Nos apresenta a ideia de risco como um dos elementos centrais, constituintes da modernidade, e nos mostra que "resultados inesperados podem ser uma consequência de nossas próprias atividades ou decisões (...) 'Risco' substitui, em grande parte, o que antes era 
pensado como fortuna (fortuna ou destino) e torna-se separado das cosmologias" (Giddens, 1991, p. 38, grifos do autor).

A cosmologia, forte religiosidade, poder do passado na forma das tradições e imediatismos, distingue as sociedades pré modernas daquelas do pós século XIX, abrindo a possibilidade da expansão das noções de risco na vida moderna. Nestas sociedades tradicionais, o futuro era absolutamente imprevisível e o destino dos povos era incapaz de estar nas mãos humanas, sendo entregue apenas à sorte dos desígnios dos deuses.

A ciência ganha aqui forte importância, ao desvendar o mundo e retirar o conhecimento das mãos dos deuses e entregar aos homens. Associando a importância das ciências com a formação do risco na sociedade contemporânea, podemos pensar que nos tempos de hoje a previsibilidade científica se impõe sobre a religião, tradição ou força da natureza. Mas, ao contrário das expectativas científicas do século XIX, que levaram à sacralização da ciência, hoje aceitamos os limites científicos diante das incertezas e a noção de risco ganha sentido na medida em que a ciência nos orienta a pensar no futuro; e seus dados nos mostram a possibilidade dos mais diferentes riscos. O mundo não necessariamente "desencantou-se" à moda weberiana, mas sim "previsibilizou-se" à ótica da ciência (Mattedi, 2006).

Assim, um mesmo evento, pensado em sociedades com a noção de destino e, posteriormente, sob a influência do risco, pode ter impactos e interpretações diferentes. Por exemplo:

"O desaparecimento das florestas é um fenômeno antigo, existente desde o momento em que foram transformadas em campos cultiváveis e cortadas de maneira inconseqüente. Mas as situações sociais e conflitos aí vinculados eram interpretados de maneira espacialmente e temporalmente delimitada, delimitação está hoje inexistente. Na medida em que se compreende e difunde socialmente que os riscos com os quais temos hoje de lidar são produzidos na esteira dos processos de modernização - isto é, que eles são produto anexo da maneira como vivemos e concebemos institucionalmente o que é "progresso", "prosperidade", etc. -, eles se tornam fundamentalmente civilizacionais, pois têm origem na forma como agimos e pensamos o "ambiente" que nos rodeia. Deste modo, as situações sociais e conflitos passam a se agremiar, enquanto conseqüências implícitas, em torno dos riscos gerados pela modernização. Por avaliação científica e midiatização do discurso científico, cada vez mais a opinião pública compreende que a existência da floresta de sua região depende também do tipo de manejo político-institucional conferido aos poluentes industriais em outro país" (Bosco, 2011, p. 14).

A produção científica passa a ser instrumento fundamental para que, na esfera do cotidiano, o indivíduo teorize os riscos, fazendo a racionalidade social fundamentar a ação da ciência - tornando-as dependentes. Difícil pensarmos a contemporaneidade sem a produção científica que nos apresenta o risco e sem legitimarmos, cotidianamente, a existência do risco mostrado via ciência.

Em suma, o passado nos apresentava uma ciência capaz de impedir os riscos, a medida em que sua busca pelas certezas e pelo conhecimento nos daria a segurança necessária para desertarmos da proteção dos deuses e trilharmos um caminho mais seguro na Terra. Porém, atualmente, muito pelos trabalhos da Sociologia da Ciência e do Conhecimento Científico, adquirimos uma postura mais cética sobre a produção dos laboratórios, afinal decisões científicas são constantemente questionadas e, por definição, são mutáveis. 
Em algumas visões, podemos pensar que a ciência que nos libertaria dos riscos se apresenta como ameaça, pois a ação antrópica pode ser promotora de riscos não existentes na natureza, por exemplo, a produção de gêneros transgênicos. Não trata-se aqui, diante deste exemplo, de tomarmos posição sobre o tema dos organismos Geneticamente Modificados (OGMs), mas relatar que estes são fruto das práticas de laboratório e não apresentam-se como consenso no meio científico, portanto apresentam uma imprevisibilidade/risco que não podemos desconsiderar (Guivant, 2001).

Para além da noção espacial do risco, podemos também pensar que este risco apresenta uma "tendência imanente à globalização" (Beck, 2001, p. 66), numa concepção que Bosco (2011) nos apresenta como perspectivas "glocais" (Robertson, 1999), onde risco globais apresentam-se efetivamente em escalas locais numa ligação ressignificante das relações espaço-tempo, presentes na contemporaneidade. Assim, efetivamente, aspectos do cotidiano (exemplo: aumento das doenças respiratórias em grandes metrópoles industriais) são contextos locais associados a riscos com aspectos globais, como a expansão da poluição do ar ou até em aspectos mais profundos como uma crise do paradigma ambiental.

No que tange à questão ambiental, a problemática do risco é central, pois parte considerável da discussão da existência dos impactos ambientais apresentam uma análise sobre impactos futuros. Assim, só pode-se debater sobre questões ambientais de posse da previsibilidade possível dos riscos futuros, diante das ações do presente e passado.

Portanto, "o termo risco denota a possibilidade de que um estado indesejável de realidade (efeitos adversos) possa ocorrer como resultado de eventos naturais ou atividades humanas" (Renn, 2008, p. 1, tradução nossa) onde, associando-se ações presentes com seus possíveis resultados futuros, temos a construção do risco na arena ambiental. Dito de outra forma, temos a noção de risco passando, necessariamente, por um julgamento antrópico, pois destas ações podemos prever o que seria efetivamente um risco ambiental. Porém, efetivamente, os resultados de muitos riscos ambientais são reais e, relativismos a parte, presente independente da questão humana, como enchentes que destroem colheitas inteiras e outros fenômenos físicos que incidem sobre o meio natural atingindo diretamente diversas sociedades.

Alguns autores trabalharam este tema, nos apresentando o que pode ser chamado de "riscos ambientais naturais" (Veyvret, 2007) ou "riscos externos (Giddens, 1999), para representar ações do meio natural que escapam da dimensão antrópica. Convém apresentar que, a evolução dos sistemas de tecnologias de informação, torna possível ampliar nossa previsibilidade sobre possíveis enchentes; modernos sistemas de engenharia possibilitam ampliar a impermeabilização de zonas urbanas, reduzindo possíveis desastres; e, até mesmo organizações institucionais, como a Defesa Civil (no caso brasileiro), são criadas para mitigar possíveis catástrofes.

Além disso, a evolução da atividade científica, como o campo da meteorologia e climatologia, torna a ciência uma aliada na constatação de eventos naturais extremos e também ousa explanar sobre possíveis causas destes, modelando até mesmo intensidade, frequência e efeitos de eventos futuros. Assim, produzindo uma nova percepção onde o "risco externo" passa a ser pensado como um "risco fabricado" (Giddens, 1999) ao alegar que, por exemplo, a ação humana - em algum nível - como na produção maciça de Gases do Efeito Estufa 
(GEEs) promove a ampliação de enchentes em determinadas áreas promovendo catástrofes. Assim, o mesmo evento (enchente) apresenta diferentes dimensões sob a ótica do risco, a medida em que novas percepções sobre ele surgem em diferentes atores dentro da arena.

\section{Risco e mudanças climáticas: o debate da percepção em Renn e da construção em Hannigan}

Conforme trabalhamos anteriormente, as mudanças climáticas representam um dos mais importantes impactos ambientais com seus riscos mundializados, ou seja, que apresentam possíveis causas promovidas por agentes presentes em todo planeta e que promove possíveis consequências globais, como o aumento da temperatura média da Terra e impactos distribuídos por praticamente todos os grupos sociais. Sendo o risco um elemento da esfera da "incerteza", podemos concluir que as incertezas dos impactos, referentes as mudanças climáticas, são compartilhadas por todo o planeta.

Afim de contribuir para o bojo teórico da Sociologia Ambiental, traremos o debate destes riscos a partir de dois intelectuais contemporâneos, que partem de concepções diferentes de como o risco é percebido/construído pelos atores: a perspectiva realista de Ortwin Renn e o construtivismo de John Hannigan.

Na perspectiva da construção social do risco, a noção do risco só apresenta sentido quando grupos humanos em suas diferentes dimensões, como o indivíduo (micro) ou sociedades (macro), conferem ao risco ambiental a importância que eles acreditam que o risco possui.
Sem negar a obviedade da existência dos impactos ambientais, no enfoque construtivista questiona-se a quem ou que grupos a degradação ambiental afeta. Parte-se do princípio de que o discurso ambiental pode ser socialmente construído. Dito de outra forma, existiriam um arcabouço ligando grupos de pressão, disputas de poder, novas centralidades que seriam responsáveis pela criação ou valorização de temáticas ambientais, centrando-se nos "processos sociais, políticos e culturais, através dos quais as condições ambientais são definidas como sendo inaceitavelmente arriscadas e, portanto, litigáveis" (Ferreira, 2006, p. 47).

Este enfoque tenta destacar a discussão ambiental nas disputas sociais que podem estar por trás das ações de grupos, fortalecendo temáticas e - muitas vezes - valorizando determinados agentes, geralmente ligados a ONG's de proteção ambiental.

Através da análise do discurso, busca-se compreender porque impactos vem à tona em determinados períodos e como são tratados e construídos. Hannigan (2009; 2012), por exemplo, parte dessa premissa para desenvolver a tese de como determinantes ambientais podem ser criados, passando por algumas etapas.

Primeiramente, um problema ambiental precisa ser validado cientificamente, a função do especialista coletando dados, cruzando informações da esfera da ciência garante a confiabilidade na questão, ou seja, não se questiona que o problema socialmente construído não exista, mas sim o que acontece daí por diante, quando essas informações saírem da esfera da ciência e chegarem até a ação política. A corrente construtivista explica que vários impactos ambientais não saíram da discussão teórica, seja por inabilidade da esfera da ciência em popularizar a temática ou pelo pouco interesse de grupos de pressão para discuti-la publicamente, 
daí a noção da construção social dos impactos ambientais.

Referindo-se as mudanças climáticas, numa perspectiva construtivista, passa-se a discutir os meios numéricos para legitimar esta como uma categoria ambiental relevante, onde "uma categoria frequentemente empregada de declarações de causas depende do uso de estimativas numéricas. Ao estabelecer a magnitude do problema, os criadores de reivindicações estabelecem sua importância, seu potencial de crescimento e seu alcance" (Hannigan, 2012, p. 104, grifos do autor, tradução livre). Assim, os dados relativos ao debate climático sempre estarem acompanhados de estatísticas como o valor do aumento de eventos extremos no planeta, ou o percentual das perdas do PIB agrícola diante da condição de aquecimento do clima, como se estas estimativas numéricas oferecessem um importante fator de legitimação do fato.

Portanto, a popularização da temática seria um esforço feito por grupos ou mesmo alguns cientistas-ativistas que retiram a discussão do campo científico e expande para outras esferas, como sociedade civil, ganhando a atenção de variados espaços de massificação da temática, como a grande mídia por exemplo, que muitas vezes faz uso de recursos visuais e simbólicos criando um atalho cognitivo e pelas imagens, não fazer uso de argumentos complexos da ciência ${ }^{5}$.

Da construção desse impacto ambiental é possível que aconteçam ações positivas visando à minimização da degradação e muitas vezes ações de continuidade e legitimidade, muitas vezes envolvendo valores financeiros, seja para sustentar ações ou viabilizar uma $\mathrm{ONG}$.

Ou seja, esses passos nos mostram como um problema ambiental pode ser socialmente construído, enquanto outros podem ser minimizados, não pela sua pouca importância, influência ou impacto, mas sim por não agradar grupos de pressão em específico ou ter a interferência de outros poderosos grupos que contestem o impacto explorado pela ciência. Por exemplo, é de propaganda global as queimadas na Amazônia, em contraponto que muito menos divulgada, porém também muito relevante, são as secas na região da África Saheliana.

Os construtivistas argumentam que, por trás do debate público sobre o meio biofísico, existe um imenso jogo de poder, em que a influência e um capital generoso estariam envolvidos, movimentando os argumentos para um lado ou para o outro. Dessa forma, grupos seriam favorecidos em detrimento de outros, usando argumentos muitas vezes emocionais para mobilizar a opinião pública, onde termos como "destruição dos mares", "destruição das florestas" e outras metáforas militares são utilizadas para se esquivar das difíceis e, muitas vezes, "frias" explicações científicas.

Ao contrário do que possa parecer numa primeira leitura, os construtivistas não são conservadores e nem negam a existência dos impactos ambientais, na verdade só acrescentam debates à uma temática que não é tão ingênua como parece e movimenta interesses, poderes e muito dinheiro. Demonstrar que os interesses ambientais são construções sociais, em nada minimizaria a relevância de mobilização para resolvê-los e a busca de uma agenda política ambientalmente sustentável, mas é

\footnotetext{
${ }^{5}$ Como exemplo, Hannigan cita a divulgação de fotos chocantes na mídia, pelo movimento ambientalista, de filhotes de focas sendo mortas com um bastão numa porção de gelo na península do Labrador, fato que atraiu a atenção da sociedade civil muitos mais do que qualquer divulgação de dados científicos e técnicos da quantidade de focas que são mortas por ano.
} 
afirmar sim, que a temática ambiental tem atores sociais ativos e mostra um caráter sociológico proeminente.

Dito de outra forma, a criação do IPCC e suas ações no debate sobre mudanças climáticas pelo mundo, seria uma mobilização promovida socialmente por grupos interessados em financiar os debates deste tema, que mesmo sendo relevante, significaria deixar a margem outros debates ambientais que porventura, sejam também importantes.

Assim, essa posição teórica, "não é só útil como uma posição teórica, mas também pode ser útil como uma ferramenta analítica" (Hannigan, 2009, p. 100), uma vez que permitiria aos pesquisadores compreender as fontes de múltiplas pressões que originariam diferentes riscos ambientais ao levar a questionamentos como "de onde um argumento [sobre o risco ambiental] vem, a quem pertence e quem administra, que interesses políticos e econômicos os argumentadores representam e que tipos de recursos eles trazem ao processo de argumentação" (Hannigan, 2009, p. 106).

Sobre isso, numa perspectiva realista, Ortwin Renn (1992a; 1992b; 2008; 2011) nos apresenta uma perspectiva interessante sobre a análise do risco, partindo da percepção que os diferentes atores apresentam de determinados riscos dentro da arena. Não convém negar a existência do construtivismo, principalmente como referência teórica, porém precisamos aceitar que os riscos efetivamente existem e que estes agem, também, a partir de relações sociais.

A existência do risco demanda a presença dos grupos humanos agindo sobre ou com o mesmo. Dito de outra forma, o risco é um elemento presente dentro da arena, que leva determinados grupos a mobilizarem seus recursos a fim de mitigarem ou se adaptarem a determinados riscos. Assim, resolvendo o debate sobre o risco como construção social ou fenômenos reais, podemos afirmar sobre isso:

\begin{abstract}
"O problema aqui é se as estimativas de risco técnico representam probabilidades de danos 'objetivos' ou apenas refletem as convenções do grupo de avaliadores de risco profissionais que não podem exigir mais grau de validade ou universalidade do que as estimativas concorrentes dos grupos de partes interessadas ou do público leigo. Além disso, diferentes culturas podem ter diferentes representações mentais do que eles consideram como 'riscos' independentes da magnitude ou probabilidade dos danos" (Renn, 2008, p. 2, tradução nossa)
\end{abstract}

A experiência do que seria o perigo e suas consequências partem de concepções mentais e, a partir delas, grupos com processos comuns criam organizações para diagnosticar e gerenciar os riscos. Portanto, organizações não governamentais, órgãos do Estado ou supranacionais, como o IPCC, não são criações arbitrárias, mas sim partes de valores culturais, institucionais, lógicos e financeiros para que existam. Portanto, observar o risco a partir das diferentes percepções dos atores e organizações, nos impede de cair na tentação do relativismo e parte da perspectiva do agente e da mobilização dos seus recursos para compreender como o risco atua.

Analisando especificamente a questão das mudanças climáticas, podemos afirmar que esta apresenta-se como um dos principais riscos ao planeta, sendo capaz de mobilizar diferentes discursos, grupos e recursos dentro da sua área específica; e se formou graças a congruência entre condições materiais da ciência e conjuntura social.

A perspectiva favorável, após os anos 1960, com a multiplicidade de organizações surgindo, associado posteriormente ao clima de otimismo pós Guerra Fria, promovendo a divulgação de dados 
sobre a questão ambiental, a disposição planetária para o debate ambiental (como a promoção da Rio92, por exemplo), levou a uma profusão de estudos sobre a questão ambiental geral e as mudanças climáticas em particular, dando voz aos cientistas e estimulando a formação de "redes" de apoio, análise e divulgação de dados sobre o tema, culminando na criação do IPCC, órgão máximo da promoção do debate sobre as mudanças climáticas no mundo. Assim, na segunda metade do século XX, a conjuntura sociocientífica promoveu a produção e disseminação das mudanças climáticas como risco, natural para uns (Lomborg, 2007) e fatal para outros (Diamond, 2005).

É uma tarefa extremamente difícil acessarmos o comportamento particular dos indivíduos diante das ameaças das mudanças climáticas, afinal o comportamento humano frente a essa questão demanda de uma série de fatores e da interação de diferentes estruturas particulares, como conhecimento do tema, proximidade com o assunto ou os meios de divulgação do mesmo, como a mídia e mesmo o interesse pela questão.

Diferentes grupos apresentam diferentes percepções sobre o risco, conforme já tratamos, afinal, um cientista deste tema tem um arcabouço de análise e capacidade de mobilizar diferentes recursos em relação a um cidadão que nunca estudou de maneira aprofundada sobre o assunto. Mas, acreditamos que esta questão, a partir da ação midiática, educacional ou pelas políticas públicas, tornou-se uma temática perceptível, portanto muito próxima da população como um todo. Mesmo sem grandes conhecimentos científicos da questão, é comum encontrarmos a associação da temática das mudanças climáticas com a existência de eventos climáticos extremos, como grandes chuvas, furacões de grande impacto ou secas pronunciadas.

Certamente a divulgação dos relatórios do IPCC colocam, pelo menos a cada 5 anos, a discussão sobre mudanças climáticas no foco dos principais assuntos debatidos na sociedade. $\mathrm{O}$ Painel funcionaria como um órgão de ressonância (Renn, 2011) sobre o tema, deixando a esfera da ciência e se incorporando, mesmo que lentamente, em outros sistemas, como na economia, política, cultura e na mídia.

A partir da divulgação dos relatórios, a questão dos riscos das mudanças climáticas ganha voz e chegam em diferentes grupos e se efetivam em diferentes ações. A questão ambiental em si, aparentemente, é um tema simpático a esfera da ação individual, seja pela amplificação dos gestos ambientais associados como uma postura saudável, ou seja, pelo temor dos efeitos nocivos que uma possível mudança no comportamento do sistema atmosféricos pode gerar.

Porém, ações individuais são pouco visíveis, apesar de amplamente estimuladas, e não são perceptíveis em níveis macros, como na esfera do Estado-nação. Este comportamento revela uma discrepância entre a consciência individual e o comportamento ambiental diante da percepção do risco na maior parte das sociedades, ao que Renn (2011) chamou de "eco-hipocrisia" (p. 162) e lista algumas causas para esse comportamento, mesmo diante da noção do risco. Existiria uma competição de valores particulares, onde parte da população, embora considere a temática ambiental importante, não vê nesse tema um valor primário, como saúde e segurança, deixando ações que minimizem o risco climático para segundo plano.

A pressão de determinados coletivos sobre a questão climática não necessariamente torna esses 
grupos referência ou destaque, tornando o tema secundário diante de grupos de pressão mais fortes sobre outros temas. Presença de distrações onde ações particulares que poderiam estar associadas com a temática ambiental se dissociam dela diante de outras questões ou distrações, por exemplo, quando ao comprar um veículo o consumidor que poderia se preocupar com a emissão de gases do efeito estufa gerada pelo carro assume outras preocupações não associadas ao comportamento individual ambiental, como status ou modelo do carro; a efetiva incapacidade individual de agir de forma ambientalmente eficaz, onde por exemplo, diante de um transporte público de péssima qualidade, o indivíduo, mesmo podendo optar pelo transporte coletivo, sente-se obrigado a usar o meio particular, mesmo que mais poluente; a existência de práticas ambientais que podem ser mal vistas pelos outros, inibindo a ação individual e ao fato de que muitas pessoas, cientes dos riscos, identificam na ação individual nenhum impacto efetivo para uma mudança mais global e espera ações em níveis macro para verificar efetividade na amenização dos risco climático, mesmo que o indivíduo tenha real consciência e percepção do mesmo.

Sobre esse último item, Giddens (2010) cita que:

"visto que os perigos representados pelo aquecimento global não são palpáveis, imediatos ou visíveis no decorrer da vida cotidiana, por mais assustadores que se afiguram, muita gente continua sentada, sem fazer nada de concreto a seu respeito. No entanto, esperar que eles se tornem visíveis e agudos para só então tomarmos medidas sérias será, por definição, tarde demais" (p. 20)
Tratando-se de um impacto global, na arena das mudanças climáticas o público atingido é um só, embora existam intensidades diferentes nos mais variados pontos do globo, temos alterações no modelo climático de escala planetária. Tratando-se de um risco para um público só, de um impacto dificilmente tangível, de consequências tratadas como distantes do presente, talvez um dos maiores desafios dos estudos em mudanças climáticas seja distanciar-se do rigor técnico e se debruçar sobre a percepção do risco dos atores e todas as questões de valores, e os julgamentos estéticos e culturais que isso acompanha. Esse é um dos níveis onde a questão ambiental apresenta sua faceta puramente social.

Diante da percepção do risco, temos as ações dos atores no interior da arena, resultando diretamente em duas consequências:

(a) os efeitos diretos que normalmente são tratados na análise de riscos técnicos, como efeitos sobre a saúde, danos materiais, custos médicos e custos de emergência; e (b) os efeitos associados à interação de tais danos com o processamento social dos eventos de risco, como estigmatização social, conflito grupal, perda de senso de comunidade e ruptura social" (Kasperson, 1992, p. 160, tradução nossa)

Assim, o efeito técnico das mudanças climáticas podem ser as análises da ampliação da concentração de GEEs desde os tempos dos estudos de Keeling, e como consequência surgiram inúmeros construtos sociais como a "estigmatização" das economias de alto carbono e a formação do próprio IPCC como instrumento de validação ou amplificação do risco das alterações dos sistemas climáticos.

Portanto, o IPCC, agindo como um agente amplificador do risco, promove o debate das mu- 
danças climáticas numa escala macro onde, diante da sua capacidade de promover uma rede complexa e extensa, age como cientista ao unir diferentes grupos técnicos dispostos a pesquisar o tema da mundialização do risco das mudanças climáticas, mas também atua como expert ou especialista, quando transmite ao público, quinquenalmente, $o$ Relatório de Avaliação e seus demais documentos.

Renn $(2008$; 2011) avalia as possibilidades apresentadas pela teoria construtivista com muita cautela e argumenta que um dos seus limites está justamente em uma das suas possibilidades. Ao transformar-se em ferramenta analítica amplia-se o relativismo sobre o risco e passamos a voltar as teorias mais para produção social do mesmo do que ao fato dele efetivamente existir e gerar impactos sobre o meio e a sociedade. Ao pensarmos o risco e sua produção apenas como um instrumento de pressão de determinados grupos, acabamos ignorando um fato básico e primordial para mitigar ou adaptar determinados riscos - o simples fato de que riscos existem.

A existência do risco só se faz presente quando o grupo social confere ao risco este status de perigo, capaz de ser quantificado ou não. Porém, isso nem sempre parte de atitudes fortemente racionais de produção de ações visando determinados benefícios, como nos levar a supor Hannigan. No exemplo que citamos anteriormente, apresentando o contraponto das queimadas amazônicas e da degradação do Sahel, vale citar que, independentemente de grupo de pressão, as queimadas na Amazônia são uma realidade e sob a ótica dos moradores locais, da ciência que se propôs a estudar aquele espaço e da produção de políticas públicas, representam um risco à comunidade, à biodiversidade, aos sistemas climáticos, etc. $\mathrm{O}$ risco do construtivismo como ferramenta analítica seria chegarmos ao ponto de ignorarmos os riscos efetivos para refletirmos apenas no seu processo de produção.

\section{Conclusões}

Conforme apresentamos, as mudanças climáticas representam um grande exemplo dos riscos ambientais mundializados contemporâneos e como todo risco apresenta-se sob a aura da incerteza. Numa comparação dos trabalhos de John Hannigan e Ortwin Renn vimos duas abordagens que partem da certeza de que riscos são reais e atingem diferentes grupos sociais. Além disso, também debatem sobre a origem dos mesmos, seja na perspectiva da produção social do risco, como comentamos sobre o construtivismo, seja na visão da percepção do risco pelos atores, conforme a perspectiva realista.

Em Hannigan, vimos que diferentes instrumentos associados com as mudanças climáticas, como o Painel Intergovernamental sobre Mudanças Climáticas (IPCC), tratar-se-ia de uma demonstração da produção social do risco, como reflexo da influência de importantes grupos de pressão, capazes de mobilizar agentes que conseguiriam financiar, seja em capital ou em conhecimento, a sustentação do Painel e seu respeito internacional. Já para Renn, poderíamos dizer que a existência do Painel, seria a demonstração da percepção do risco em escala planetária, de onde redes político-científicas integraram-se para produção de um órgão de amplificação ou ressonância da temática das mudanças climáticas num nível planetário. Para Hannigan, a influência de atores e instituições, em algum nível, seria peça chave para compreender a promoção do risco, enquanto em Renn temos que 
inicialmente a percepção do risco seria o segredo para se compreender a mobilização dos diferentes atores.

Visando colaborar para os estudos sobre risco e incertezas, julgamos ser de grande valia a compreensão de como os atores orientam suas ações diante de riscos ou incertezas, sejam locais ou em escala planetária, como tratamos aqui, e acreditamos que as abordagens apresentadas oferecem um bom ponto de partida para compreensão disso.

\section{Agradecimentos}

Agradeço imensamente os ricos debates propiciados pelo GT34 (Teoria Sociológica) da Sociedade Brasileira de Sociologia (SBS) e pelo espaço aberto para a apresentação de artigos relacionados à construção teórica na área de Ambiente e Sociedade.

\section{Referências}

Andrade, T. H.; Almeida Junior, A. (Orgs.). Mídia e Ambiente: estudos e ensaios. São Paulo: Hucitec, 2011.

Bacchiegga, F. Quando a Ciência Vira Notícia: uma análise sociológica da divulgação do $4^{\circ}$ relatório do IPCC pela imprensa brasileira. Tese (doutorado em Ciências Sociais) - Universidade Estadual de Campinas, Instituto de Filosofia e Ciências Humanas, 2017 (no prelo)

Beck, U. La sociedad del riesgo: hacia uma nova modernidad. Barcelona: Paidos, 2001.

Bosco, E. Ulrick Beck: a teoria da sociedade de risco mundial. Dissertação (mestrado em Sociologia) - Universidade Estadual de Campinas, Instituto de Filosofia e Ciências Humanas, Campinas, 2011. Disponível em: http://www. bibliotecadigital.unicamp.br/document/?code $=000797859$. Acesso em: 5 jun. 2015.

Diamond, J. M. Armas, germes e aço: os destinos das so- ciedades humanas. 15. ed. Rio de Janeiro, RJ: Record, 2005

Ferreira, L. Ideias pra uma Sociologia da Questão Ambiental no Brasil. São Paulo: Annblume,2006.

Giddens, A. As consequencias da modernidade. São Paulo, SP: UNESP, 1991.

Giddens, A. Risk. Reith Lectures BBC, 1999. Disponível em: http://news.bbc.co.uk/hi/english/static/events/reith_99/ week2/week2.htm Acesso em: 02 jun. 2015.

Giddens, A. A política da mudança climática. Rio de Janeiro, RJ: Jorge Zahar, 2010.

Gorz, A. Ecology Politics. Londres: Pluto, 1980.

Guivant, J. S. A teoria da sociedade de risco de Ulrich Beck: entre o diagnóstico e a profecia. Estudos Sociedade e Agricultura, 2001.

Hannigan, J. Sociologia Ambiental. . Ed. Vozes. Petrópolis, 2009.

Hannigan, J. Disasters without Borders: the international politics of natural disasters. Polity Press, Cambridge, UK, 2012

Ianni, O. Teorias da Globalização. Rio de Janeiro, Civilização Brasileira, 1995.

Illich, I. A Convivencialidade. Publicações Europa/ América. Lisboa, 1976

IPCC. Principles Governing IPCC Work., 2013 Disponível em https://www.ipcc.ch/pdf/ipcc-principles/ipcc-principles. pdf. Acesso em 04 jun. 2015.

Kasperson, R. E. The Social Amplification of Risk: progress in developing na integrative framework. In: Krimsky, S.; Golding, D. Social Theories of Risk. London: Praeger, 1992.

Keeling, C. D. "The concentration and isotopic abundances of carbon dioxide in atmosphere" Telus. Vol XII, 1960.

Keeling, C. D. "Climate Change and carbon dioxide: an introduction". Proceedings of the National Academy of Sciences, 94, Stanford University's Highwire Press, Boston, 1997.

Lomborg, B. Cool it: the skeptical environmentalist's guide to global warming. New York, NY: Alfred A. Knopf, 2007.

Mattedi, M. Sociologia e Conhecimento: introdução à abor- 
dagem sociológica do problema do conhecimento. Chapecó, SC, Argos, 2006.

Mol, A. "A Globalização e a mudança dos modelos de controle e poluição industrial: a teoria da modernização ecológica”. In: Freitas, C. M. de; Porto, M.; Herculano, S. (Orgs.). Qualidade de Vida \& Riscos Ambientais. Eduf. Niterói, 2000.

ONU. Resolution 43/53 General Assembly, 1988 Disponível em http://www.un.org/documents/ga/res/43/a43r053.htm Acesso em 03 jun. 2015.

Ortiz, R. Mundialização: saberes e crenças. São Paulo, SP: Brasiliense, 2006.

Renn, O. Concept of Risk. In: Krimsky, S.; Golding, D. Social Theories of Risk. London: Praeger, 1992a

Renn, O. The Social Arena Concepto f Risk Debates. In: Krimsky, S.; Golding, D. Social Theories of Risk. London: Praeger, 1992b
Renn, O. Risk governance: coping with uncertainty in a complex world. London: Earthscan, 2008.

Renn, O. The Social Amplification/Attenuation of Risk Framework: application to climate change. Wiley Interdisciplinary Reviews: Climate Change, 2011

Robertson, R. Globalização: teoria social e cultura global. Petrópolis, RJ, Vozes, 1999.

Schnaiberg, A. Local Environmental Struggles: citizen activismin the treadmill of production. New York, Cambridge University Press, 1996

Spaargaren, G; Mol, A; Buttel, F. Environment and Global Modernity. New Delhi, Thousand Oaks. 2000

Veyvret, Y. (Org.). Os riscos: o homem como agressor e vítima do meio ambiente. São Paulo, SP: Contexto, 2007. 